\title{
Zum Tode von Dr. med. Konrad Betz
}

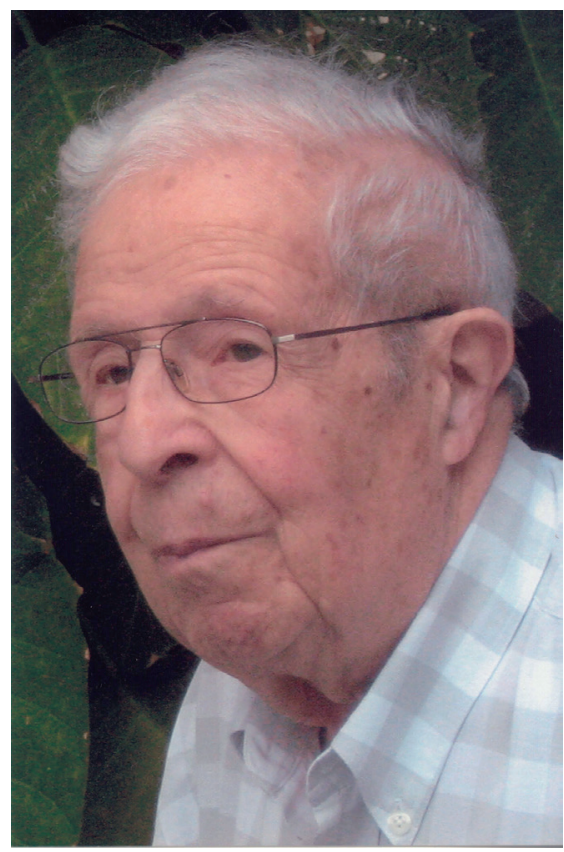

Am 25. Februar 2013 verstarb Dr. med. Konrad Betz im hohen Alter von fast 95 Jahren.

Am 29. September 1918 in Herrentierbach im Hohenlohischen geboren und mit sechs Geschwistern im Pfarrhaus aufgewachsen, wählte er das Medizinstudium, obwohl er zusammen mit seinem älteren Bruder im Theologischen Seminar in Tübingen erzogen wurde. Beim Kriegseinsatz 1939 in Sewastopol arbeitete er bereits als Assistenzarzt. Nach einem halben Jahr Kriegsgefangenschaft in den USA begann er mit der zehnjährigen klinischen Fachausbildung. Danach ließ er sich 1956 in Schwäbisch Hall nieder. Von seinen Kollegen als äußerst qualifiziert und warmherzig geschätzt, waren ihm Verantwortungsbewusstsein und das Wohl seiner Patienten oberste Gebote.

1984 zog er sich fast ganz aus dem beruflichen Leben zurück, und sein Bedürfnis, Historisches zu erforschen, nahm von da an einen breiten Raum in seinem Alltag ein.

Konrad Betz war eng mit seiner hohenlohischen Heimat verbunden und setzte ihr mit seinem Buch „Hohenloher Merk-Würdigkeiten“ ein bleibendes Denkmal. Es ist ein Gang durch Hohenlohe mit wachen Augen, viel Detailkenntnissen und mit Herzblut geschrieben. Er zeigt sich dabei als ein ausgezeichneter Kenner Hohenlohes in Bezug auf seine Menschen, seine Geschichte, Kunstgeschichte, Natur und Landschaften.

Viele Jahre war er Beauftragter für die Sammlungen des Historischen Vereins, und häufig vertrat er den Verein bei offiziellen Veranstaltungen. Sein kluger Rat war in der „Montagsrunde“, den regelmäßigen Zusammenkünften des Vereinsvorstandes und dessen Berater, stets gefragt und seine ausgleichende Art geschätzt. Mit seiner hohen Intelligenz, seiner Bescheidenheit und seiner Fähigkeit, auf Menschen zuzugehen, war er in der Lage, eine Atmosphäre des Vertrauens zu schaffen.

Wir verlieren mit ihm einen liebenswürdigen, mit seiner hohenlohischen Heimat eng verbundenen Freund. 
An seinem 93. Geburtstag - den Abschied wohl schon vorausnehmend - sprach er mit seinen eigenen Worten dieses kurze Gedicht zu seinen Gästen:

Wo ich einst ruhen will? Du fragst?

Ich weiss schon lang - im Herz der Jagst.

Die Staufer-Reichsburg Leofels,

Riesen-Ruine! Doch noch hält's.

Frühgotische Fenster an der Wand,

Mords-Buche, wo der Bergfried stand.

Unten im Tal liegt Hessenau.

Mittlerer Muschelkalk, genau!

Nur ein paar Häuser. Schmale Brücke.

Bauminseln. Kleine Wiesenstücke.

Jagstaufwärts Linden-Ahorn-Wald.

Da ruh ich - bald.

Seine letzte Ruhe fand unser langjähriges Vereinsmitglied und enger Vertrauter auf dem Waldfriedhof in Schwäbisch Hall.

Ernst Breit 